\title{
JUNIOR RED CROSS MEETING IN BELGRADE
}

The International Junior Red Cross Meeting, organized by the Red Cross of Yugoslavia, took place in Belgrade between 4 and 9 September, and was attended by 49 delegations. Of these, forty had been sent by recognized National Societies, and two by Societies not yet recognized. Four delegations represented liberation movements or the Red Cross group of such a movement. The meeting was also attended by representatives of the League of Red Cross Societies, the Henry Dunant Institute and the ICRC. Discussions at the Meeting followed the general theme: "Youth and the growth of the Red Cross, contribution to peace and progress in the world".

After the inaugural ceremony, which included an address by Dr. B. Raspopović, President of the Assembly of Vice-Presidents of the Red Cross of Yugoslavia, the participants gathered several times in plenary session to hear the delegations' reports on the activities of their own youth groups within the National Societies. The resulting discussion, which was thorough and wide-ranging, lasted for over a day. A drafting committee then drew up a final report in which the delegates clearly affirmed their respect for and attachment to the fundamental principles of the Red Cross.

\section{THE RED CROSS AND RADIOCOMMUNICATIONS}

The need for the ICRC to have its own radio system to guarantee the speed and effectiveness of its operations had long been obvious. In 1959, the Administrative Conference on Radiocommunications in Geneva recommended that the Red Cross should have an autonomous radio 
system. In 1965, at Vienna, the Twentieth International Conference of the Red Cross passed a resolution encouraging the development of Red Cross telecommunications.

Since the establishment in 1963 of the ICRC's radio station with the call signal HBC-88 and the first exchange of messages between ICRC headquarters and its delegation in Yemen (1963-1964), there has been continual progress. ${ }^{1}$ The ICRC is now in regular daily contact with its delegations in many parts of the world. Following this example, 43 National Red Cross Societies have set up their own radio systems, either for communications with other Societies or for their own domestic purposes.

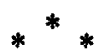

In Geneva, the ICRC has its main sending and receiving station at Versoix, in the countryside about 10 kilometres from headquarters, to which it is linked by telex and telephone. Another station, at headquarters, can be used when the Versoix station is overloaded.

The ICRC also has a workshop for minor repairs and a storehouse with equipment ready for shipment. Material on hand is worth some 500,000 francs. The ICRC is thus in a position to provide material at short notice to departing emergency delegations or to replace equipment in the field which is out of order. In 1976, seven fully equipped radio stations and about 200 shipments of spare parts were sent from Geneva to ICRC delegations abroad.

In the world as a whole, at the end of 1976 , the ICRC had 18 transmitter-receiver stations, 12 of which were in direct contact with headquarters, while the others were in touch through relay stations.

The events in Lebanon have entailed the transmission of a great number of messages. From Geneva, there are from 4 to 7 communications daily with the ICRC delegation in Beirut, 3 with Tripoli and 2 with Jounieh. There are also 2 daily contacts with Cairo and 3 with Amman, the latter relaying messages to Damascus. All these stations communi-

${ }^{1}$ International Review has published several articles on developments in this field, in January 1971, March and November 1972 and March 1975, for example. 
cate messages as well between one another. They can also exchange messages with the ICRC stations at Nicosia and Jerusalem, which have no direct contact with Geneva.

Farther east, the ICRC has a station at Rawalpindi, which relays messages to and from stations in New Delhi and Dacca, and another at Vientiane, serving as a relay station for Bangkok. The Vientiane station can also transmit messages to the ICRC delegation at Hanoi, but only by telex. It is hoped shortly to open a station at Kuala Lumpur for the regional delegation in Malaysia.

In Africa, the ICRC has three stations, in Lusaka, Salisbury and Nairobi. It has two in Latin America, at Caracas and Santiago. A third station is planned for Guatemala, where a regional delegation has its headquarters.

In 1976 , there were 11,871 messages exchanged between Geneva and stations in the field, amounting to a total of 768,197 words. These figures do not include radio voice conversations, which take place exceptionally.

Exchanges between delegations were even more voluminous: 23,739 messages and a total of 800,418 words.

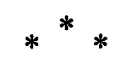

To add to the foregoing, it should be noted that the ICRC also makes great use of telex, particularly with delegations which, for a variety of technical reasons, do not have radio stations, such as those in Tel Aviv, New York and elsewhere. About 6,200 messages were sent from Geneva and a like number were received.

Relatively few people are employed to operate the ICRC's radio network. In Geneva and Versoix, for the two sending and receiving stations, storehouse, repairs shop, telex service and technical maintenance, it has seven full-time staff members, with temporary personnel filling in as required, especially on weekends. Every radio operator can also operate the telex-and if necessary function as an accountant or administrator.

For service with delegations abroad, the ICRC must often send operators from Switzerland. There were 19 such assignments in 1976. For the most part, these are persons who are willing to give up their regular work for a few months to serve the ICRC. Among them are often radio amateurs, whose day-to-day work is entirely different from that performed with the overseas delegations. Through their devotion to a humanitarian cause and their enthusiasm for radio, they make excellent operators on short-term assignments lasting for a few months. In 
addition, since radio transmissions do not take all their time, they also turn their hands to work as bookkeepers, administrators, relief distributors or photographers.

The ICRC radio service also tries to recruit operators in the countries where they are to work. Thus, it has local radio operators in Cairo, Jerusalem, Rawalpindi and elsewhere. But it is often difficult for these locally engaged operators to work in other languages than their own, which creates a problem for such recruitment.

When traffic with a station is relatively sparse, it is often a delegate who is responsible for his own communications.

For all people who are not regular staff members of the ICRC, special preparatory courses must be given, dealing with a number of subjects. In addition to basic teaching about the Red Cross and the ICRC, they must learn about the specific purposes of the missions of which they are a part; how to act under a variety of circumstances, often dangerous, which may arise. Finally, they must learn the rules for ICRC messages - for it is obvious that the wavelengths assigned to the Red Cross by the International Telecommunication Union must not be used for frivolous messages or to "pass the time of day". Messages of a commercial or political nature are also forbidden, for the messages of the Red Cross are exclusively of a humanitarian character.

The next Worldwide Administrative Radio Conference of the ITU will open in Geneva on 24 September 1979.

Since the Red Cross set up its own emergency radiocommunications network, it has been amply demonstrated that Red Cross action of any significance must be able to rely on a direct, swift and independent telecommunications system.

Point 3 of Recommendation No. 34 relating to the use of radiotelegraph and radiotelephone links by Red Cross organizations, which was approved by the previous Administrative Radio Conference, held in 1959, recommended that the next Conference should consider whether any further action was necessary.

In 1963, the Swiss Telecommunications Administration authorized the ICRC to broadcast on five frequencies. Some years later, five further frequencies were granted, a single channel in each band having become inadequate, especially as channels had to be shared at times with commercial, military and consular services. 
On the grounds that the low power of its transmitters does not interfere with other transmissions and that its broadcasts are of a strictly humanitarian character, the Red Cross intends to ask the 1979 Conference to agree that ten frequencies be exclusively allocated to the Red Cross and that Recommendation 34 be supplemented by a new resolution.

With this objective in mind, National Red Cross Societies are urged to bring this project to the attention of the various authorities concerned in their respectives countries, stressing how important it is for the Red Cross to have an emergency radio network to ensure maximum efficiency in its humanitarian operations. 